Article

\title{
Application of Protection Motivation Theory to Investigate Waste Management Behaviors of Public and Private Officers in Bangkok City, Thailand
}

\author{
Piyapong Janmaimool
}

Environmental Social Science Program, Department of Social Sciences and Humanities, School of Liberal Arts, King Mongkut's University of Technology Thonburi, Bangkok 10140, Thailand ; piyapong.jan@kmutt.ac.th, tum16615@hotmail.comcom; Tel.: +6698-919-9559; Fax.+662-428-3375

\begin{abstract}
This study aims to explain individual engagement in sustainable waste management behaviors (SWMBs) based on the application of protection motivation theory (PMT). SWMBs include waste avoidance, green purchasing behavior, reuse and recycle, and waste disposal behaviors. This study applies PMT to explore how individuals' SWMBs are influenced by their perceived threats caused by environmental contamination from waste disposal and their perceived coping capability. The Bangkok metropolitan area was selected as a case study because it has faced serious waste management problems caused by massively increasing amounts of solid waste during the last ten years. Questionnaire surveys were conducted with 193 public and private officers residing in the city of Bangkok. The one-way analysis of variance (ANOVA) was performed to justify the effect of individual threat appraisal and coping appraisal on the engagement in SWMBs. The results demonstrated that respondents' self-efficacy highly influenced all types of SWMBs. The perceived probability of being impacted from pollutants influenced all of the SWMBs except green purchasing behaviors. Response efficacy did not influence all SWMBs; however, the perceived severity of adverse consequences caused by pollutants highly influenced reuse and recycle behaviors. It could be suggested that PMT is well suited for investigating low-cost and simple SWMBs. It could also be suggested that different communication campaigns should be established to enhance citizens' engagement in each type of SWMB.
\end{abstract}

Keywords: sustainable waste management behaviors; protection motivation theory; pro-environmental behaviors; threat appraisal, coping appraisal

\section{Introduction}

Numerous cities throughout the world face environmental problems caused by massively increasing amounts of solid waste. Bangkok, the capital city of Thailand, is one of those cities. In 1997, the average amount of waste recorded by the Bangkok Metropolitan Administration (BMA) was about 8,500 tons/day, double the amount of waste recorded in 1987, at 4,200 tons/day. Although BMA spent a tremendous amount of money dissolving this massive amount of waste, they were simultaneously forced to search for more sites for waste disposal. BMA put significant effort into solving this problem and the waste management issue was finally included in the Fifth Bangkok Development Plan (1997-2001) [1], where two main waste management strategies were emphasized. The first strategy was the Waste Minimization Project; its purpose was to reduce the amount of solid waste by encouraging residents to reduce and separate waste before disposal [2]. The second strategy, the Middle Term Disposal Plan (1997-2006), aimed to develop a waste disposal system. Although the strategies were widely implemented by all 50 districts, the outcomes were not extremely satisfactory. This was evidenced by the amount of waste in 2015, more than 10,000 tons/day, and that was a combination of several different types of waste. Currently, the amount of waste is still steadily increasing and waste disposal in the landfills has caused both environmental 
and health risks to residents. The city of Bangkok urgently needs to require effective solid waste management measures.

The waste management behaviors of citizens can play an important role in solving waste management problems by minimizing the volume of solid waste and effectively eliminating waste without leaving any impact on the environment [3]. The concept of a waste hierarchy, which is widely used to explore effective solid waste management [4-6], suggests three main strategies for achieving sustainable waste management: avoidance, resource recovery, and disposal [3]. Avoidance, the highest priority, refers to action to minimize the volume of waste produced by individuals, the industrial sector, and/or public and private organizations. Individuals, for instance, should purchase environmentally friendly products or products that are produced from the fewest resources. If avoidance cannot be carried out, resource recovery practices are suggested. This means increasing the options for reuse, recycling, and reprocessing. Examples of reuse activities include double-sided printing, using single-sided paper for writing notes, and reusing plastic bags [7]. If neither waste minimization nor reuse can be performed, recycling waste should be considered. Several types of material, such as paper, glass, and plastic could be transformed into other usable products. In addition, energy recovery from waste is also proposed since it was found that waste could be used to generate fuel and energy through a waste incineration process [8]. However, some types of waste, particularly hazardous waste, are not easy to reuse and recycle. Therefore, the last priority, disposal, is suggested. Here, disposal includes all disposal options that are carried out based on the notion of environmental responsibility and avoidance of environmental impacts. Disposing of solid waste in a landfill is the least desirable strategy due to the high possibility of yielding environmental impacts [9]. Similar to the waste hierarchy of the US-EPA, the EU waste hierarchy suggests five possible ways to practice waste management: reduction, reuse, recycle, recovery, and disposal [10]. All of these strategies can be implemented at all levels, from the individual to the municipality level.

Several theoretical perspectives were derived to investigate which factors determine citizens' engagement in sustainable waste management behaviors. The theory of planned behaviors (TPB), initiatively proposed by Ajzen in 1991, explains that individuals' pro-environmental behavior (PEB) is influenced by behavioral intention, which is based on three important factors: subjective norms, attitudes toward behaviors, and perceived behavioral control [11]. Stern proposed the Stern's value belief norm (VBN) theory in 1999; it included the moral dimension of the human decision-making process and perceived environmental values [24]. The theory of interpersonal behavior (TIB) includes emotive and habitual perspectives. In this study, the protection motivation theory (PMT) $[12,13]$ addressing another theoretical perspective of PEB is specifically investigated and discussed. Originally developed to predict people's engagement in health risk prevention [13, 14], PMT proposes motivational factors that may influence individuals' environmental attitudes and pro-environmental behaviors. Based on PMT, when confronted with environmental and health risks, individual decisions to engage in preventative actions are made based on perceived risk vulnerability and the severity of the adverse consequences on the one hand, alongside considering the potential to minimize those risks through response efficacy and self-efficacy on the other hand. In considering the environmental risks that are potentially generated during the process of waste disposal, it was found that leachate and gas derived from waste disposal in landfills could potentially cause diverse environmental and health impacts such as explosions, vegetable damage, odors, polluted ground water, and polluted air [15]. Therefore, it is possible that individuals' perceived risks and the capacity to manage those risks will influence their decision to take part in waste management behaviors.

This study aims to investigate citizens' engagement in sustainable waste management behaviors, which include waste avoidance, green purchasing behaviors, reuse and recycle, and waste disposal behaviors. In addition, the study also investigates how perceived environmental risks caused by waste disposal and perceived capability to manage those risks influence citizens' engagement in SWMB. Finally, the study proposes communication strategies that could promote SWMB. 


\section{Protection Motivation Theory and Conceptual Idea of the Study}

The protection motivation theory (PMT), first introduced by Rogers [12], proposes a conceptual framework to explain factors predicting risk preventative behaviors. PMT assumes that an individual's decision to participate in risk preventative behaviors is made based on their motivation to protect themselves from threatening harm. People balance different risks and potential benefits. The decision is made based on the results of threat appraisal and coping appraisal [13]. Threat appraisal is a cognitive process that individuals use to estimate the risk that they face. It includes two important elements: assessment of the perceived severity of the threat and the perceived probability of receiving adverse impacts from the threat (vulnerability). Perceived severity of the threat means the degree of seriousness of an existing risk that is perceived by an individual. Perceived vulnerability means an individual's perceptions of their susceptibility to the existing threatening events. Threat appraisal also includes the perception of the reward, which refers to perceived benefits of current practices (not engaging in risk preventative behaviors). It is assumed that higher perception of severity and vulnerability is likely to enhance individual motivation to perform risk preventative behavior, while higher perception of rewards from current practices will inhibit risk preventative behaviors. In addition to threat appraisal, coping appraisal, which refers to the estimation of an individual's capacity to perform risk preventative behaviors, also influences the protection motivation. The coping appraisal includes self-efficacy and response efficacy. Self-efficacy is an individual's perception of their capability to perform the behaviors. Response efficacy refers to the perceived effectiveness of the recommended risk preventative behaviors. Coping appraisal also considers the response cost, which is the cost of performing the recommended behavior [13]. A high cost of performing preventative behaviors might hinder people from being involved in recommended behaviors. The coping appraisal is the sum of the appraisals of the self-efficacy and the response efficacy minus the costs of performing the recommended preventive behavior. In sum, it can be concluded that the protection motivation is influenced by the outcome of the threat appraisal and the coping appraisal. PMT is primarily applied to explain people's decision to partake in health risk mitigation behaviors [16, 17] and disaster prevention [18-20].

\section{Conceptual Idea of the Study}

Since the waste disposal process potentially yields environmental and health risks [15], it is possible that an individual's threat appraisal and coping appraisal, as indicated in PMT, will influence their engagement in waste management behaviors. Therefore, this study intends to prove whether PMT is applicable to explaining waste management behaviors. Four independent variables were developed and examined to ascertain whether they could predict the level of engagement in waste management behaviors. Two independent variables are related to threat appraisal: the first is the perceived severity of adverse consequences potentially caused by environmental impacts of waste disposal and the second is the perceived probability of receiving impacts from contaminated environments. Another two independent variables related to coping appraisal are self-efficacy and response efficacy. Investigations on the relationship between citizens' engagement in waste management behaviors and these four variables are expected to provide the implications for the development of communication strategies that enhance citizens' waste management practices. The proposed relationship between the dependent and the independent variables is shown in Figure 1. It is assumed that individuals who exhibit a high level of perceived risks and perceived self-capability would be more active to perform waste management behaviors. 
Threat Appraisal

Perceived severity of adverse consequences caused by environmental contamination

Perceived probability of receiving impacts from contaminated environments

\begin{tabular}{l} 
Coping Appraisal \\
Self-efficacy \\
\hline Response efficacy
\end{tabular}

\section{Level of engagement in}

waste management

\section{behaviors}

Waste avoidance behaviors

Green purchasing behaviors

Reuse and recycle

behaviors

Waste disposal behaviors

Figure 1. Conceptual idea of the study

\section{Research Method}

In this study, the dependent variable was defined as citizens' engagement in each type of waste hierarchy behaviors. These behaviors were divided into four categories: waste disposal, green purchasing, waste avoidance or reduction, and reuse and recycle behaviors (see Table 1). The literature review reveals that many scholars employ individual self-reports when developing questionnaire items. Numerous studies showed that a self-report is an effective tool for measuring actual environmental behavior [21, 22]. This study employed self-reports to collect data for measuring the dependent variable. Respondents were asked to indicate the frequency of their involvement in a list of waste management behaviors. The study developed a list of questions, adapted from Boer and Seydel [23], to measure the independent variables. Respondents were asked to indicate the degree of perceived severity of adverse consequences caused by environmental impacts of waste disposal, the perceived probability of receiving impacts from contaminated environments, the degree of self-capability to perform waste management behaviors, and the perceived capability of waste management behaviors to mitigate environmental impacts. The sample group for this study included 193 people who work in a public or private company and permanently live in the city of Bangkok. The respondents were asked to complete a questionnaire, either online or using a questionnaire sheet. The analyses of variances (ANOVA) were performed to inspect and analyze all of the collected data. The results demonstrate how each variable related to PMT influences citizens' waste management behaviors.

Table 1. Factors, variables, and development of questionnaire.

\begin{tabular}{|c|c|c|c|}
\hline Factors & Variables & Survey questions & $\begin{array}{l}\text { Response } \\
\text { categories }\end{array}$ \\
\hline \multirow{4}{*}{$\begin{array}{l}\text { Level of } \\
\text { engagement in } \\
\text { hierarchy } \\
\text { waste } \\
\text { management } \\
\text { behaviors }\end{array}$} & $\begin{array}{l}\text {-Waste disposal } \\
\text { behaviors }\end{array}$ & $\begin{array}{l}\text { How often do you separate waste into the proper categories before } \\
\text { throwing it away in bins? } \\
\text { Have you ever thrown the liquid from a container away before throwing } \\
\text { the container away? }\end{array}$ & \multirow{4}{*}{$\begin{array}{l}1=\text { No } \\
\text { involvement } \\
5=\text { Regular } \\
\text { involvement }\end{array}$} \\
\hline & $\begin{array}{l}\text {-Green purchasing } \\
\text { behaviors }\end{array}$ & $\begin{array}{l}\text { Have you avoided buying food packaged in foam containers? } \\
\text { During the past year, how often have you purchased environmentally } \\
\text { friendly products, such as organic products, biodegradable detergents, } \\
\text { and returnable containers? }\end{array}$ & \\
\hline & $\begin{array}{l}\text {-Waste avoidance } \\
\text { behaviors }\end{array}$ & $\begin{array}{l}\text { How often do you use a cotton bag instead of plastic bags? } \\
\text { Have you ever refused to receive a plastic bag when you buy a few items? } \\
\text { Have you used a reusable instead of a single use container? }\end{array}$ & \\
\hline & $\begin{array}{l}\text {-Reuse and recycle } \\
\text { behaviors }\end{array}$ & $\begin{array}{l}\text { How often do you reuse or recycle things such as plastic bags and bottles? } \\
\text { Have you ever done double-sided printing and used single-sided paper } \\
\text { for writing notes? }\end{array}$ & \\
\hline \multirow{4}{*}{$\begin{array}{l}\text { Threat } \\
\text { Appraisal }\end{array}$} & $\begin{array}{l}\text {-Perceived severity of } \\
\text { adverse consequences } \\
\text { caused by }\end{array}$ & $\begin{array}{l}\text { How severely can environmental pollutants caused by waste disposal } \\
\text { affect humans? }\end{array}$ & \multirow{4}{*}{$\begin{array}{l}1=\text { Low } \\
4=\text { Very high }\end{array}$} \\
\hline & environmental & \multirow[b]{3}{*}{ What is the possibility that pollutants will impact you? } & \\
\hline & contamination & & \\
\hline & $\begin{array}{l}\text {-Perceived probability } \\
\text { of receiving impacts } \\
\text { from contaminated }\end{array}$ & & \\
\hline
\end{tabular}


environments

\begin{tabular}{llll}
\hline Coping & -Self-efficacy & $\begin{array}{l}\text { Is it possible that you will be able to significantly change your behaviors } \\
\text { into sustainable waste management behaviors? }\end{array}$ & $\begin{array}{l}1=\text { Low } \\
\text { Appraisal }\end{array}$ \\
& -Response efficacy & $\begin{array}{l}\text { Do you think a single person's actions can contribute to the improvement } \\
\text { of environmental quality? }\end{array}$ & \\
\hline
\end{tabular}

\section{Results}

\subsection{Characteristics of Respondents}

The socio-demographic characteristics of the respondents are depicted in Table 2 . The number of female respondents was higher than that of male respondents, at $64.2 \%$ and $35.8 \%$, respectively. The average age of the respondents was 30.5 years old. The survey results showed that most of the participants, more than $40 \%$, had an average income of between 15,000 and 30,000 Baht. This amount coincides with a standard income for a person holding a bachelor's degree. The percentage of respondents with an average income of between 30,001 and 50,000 Baht, which was considered as a high income, was almost $25 \%$; whereas, only $6.2 \%$ had a low income, less than 10,000 Baht. The majority of the participants, approximately $59 \%$, worked with a private company, and $36.8 \%$ worked with a public organization. As to the respondents' education level, almost $60 \%$ of the participants have a bachelor's degree and $37.8 \%$ have a master's degree. The average period of time living in Bangkok was 18.5 years.

Table 2. Socio-demographic characteristics of the respondents.

\begin{tabular}{lll}
\hline Items & Mean/N & $\mathrm{SD} /(\%)$ \\
\hline Gender & & \\
$\quad$ Male & 69 & $35.8 \%$ \\
$\quad$ Female & 124 & $64.2 \%$ \\
\hline Age & 30.5 & \pm 7.5 \\
\hline Income (Baht) & & \\
$\quad$ less than 10,000 & 12 & $6.2 \%$ \\
$\quad$ 10,000-15,000 & 23 & $11.9 \%$ \\
& & \\
15,001-30,000 & 83 & $43.0 \%$ \\
$\quad 30,001-50,000$ & 48 & $24.9 \%$ \\
$\quad$ More than 50,000 & 27 & $14.0 \%$ \\
\hline Career & & \\
\hline Private Company & 114 & $59.1 \%$ \\
$\quad$ Public Organization & 71 & $36.8 \%$ \\
$\quad$ Public-Private & 8 & $4.1 \%$ \\
Company & & \\
\hline Period of Time Living in & 18.5 & \pm 11.9 \\
BKK & & \\
\hline Education Level & & \\
$\quad$ High School & 15 & $7.8 \%$ \\
Bachelor's & 94 & $48.7 \%$ \\
$\quad$ Master's & 73 & $37.8 \%$ \\
Doctorate & 11 & $5.7 \%$ \\
\hline Notes: N=193 & & \\
$\quad$ & &
\end{tabular}

\subsection{Influence of Threat Appraisal and Coping Appraisal on Respondents' Engagement in SWMBs}

One-way ANOVA analyses were performed to test whether respondents who exhibited a different level of perceived response efficacy, self-efficacy, severity of adverse consequences, and vulnerability relatively reported a significantly different level of engagement in SWMB. Considering the effect of perceived response efficacy on the level of engagement in SWMBs, the tests of homogeneity of variances were performed first. These showed equal variances across groups (sig > 0.05) in all types of SWMBs, except green purchasing behaviors, which had unequal variances across groups (sig $\leq 0.05$ ) (see Table 3). With the green purchasing behaviors, the results of Welch's t-test 
were used instead of the regular ANOVA test. These results showed that the levels of engagement in green purchasing behaviors did not significantly differ among respondents exhibiting different degrees of response efficacy, $F(3,63.086)=1.949, p=0.131$. For the other types of SWMBs, the results of the ANOVA tests also revealed no significant difference in the level of engagement in SWMBs among respondents who exhibited a different degree of perceived response efficacy.

Considering the effect of self-efficacy on the level of engagement in SWMBs, the test of homogeneity of variances showed equal variances across groups (sig $=0.001)$ in all types of SWMBs. The results of the ANOVA tests were therefore used; these results revealed that there was a significant effect of self-efficacy on the level of engagement in all types of SWMBs. Clearly, self-efficacy has a significant effect on the level of engagement in waste disposal behaviors, $\mathrm{F}(3,189)$ $=9.09, \mathrm{p}=0.000$. Post hoc comparisons using the LSD indicated that the mean score of the engagement in waste disposal behaviors for high and very high perceived self-efficacy was significantly higher than for moderate and low self-efficacy. However, the mean score for low perceived self-efficacy did not differ significantly from that of moderate self-efficacy, and the mean score for high perceived self-efficacy did not differ significantly from that of very high self-efficacy. The level of self-efficacy also had a significant effect on green purchasing behaviors, $\mathrm{F}(3,189)=6.73$, $p=0.000$. The results of the post hoc test showed that the mean score of engagement in green purchasing behaviors for very high and high perceived self-efficacy was significantly higher than that of moderate and low perceived self-efficacy. Considering the effect of self-efficacy on the respondents' reuse and recycle behaviors, according to the results of the ANOVA test, there was a significant effect of self-efficacy on the levels of engagement in reuse and recycle behaviors at $\mathrm{P}<$ $0.05, \mathrm{~F}(3,189)=4.29$. Post hoc comparisons indicated that only the mean score for high perceived self-efficacy was significantly higher than that of moderate self-efficacy. Other comparisons did not show a significant difference. Finally, self-efficacy also had a significant effect on the engagement in waste avoidance behaviors, $F(3,188)=3.32, p=0.021$, and the result of the post hoc test indicated that the mean score for high perceived self-efficacy was significantly higher than that of moderate and low perceived self-efficacy. Other comparisons did not show statistically significant results.

Table 3. Differences in means of SWMB engagement scores given by respondents who exhibited different levels of estimated coping capacity.

\begin{tabular}{|c|c|c|c|c|c|c|c|c|c|}
\hline \multirow{2}{*}{ SWMB } & \multirow{2}{*}{ Coping appraisal } & \multicolumn{4}{|c|}{ Response efficacy } & \multicolumn{4}{|c|}{ Self-efficacy } \\
\hline & & $\mathrm{N}$ & Mean & SD & Statistics & $\mathrm{N}$ & Mean & $\mathrm{SD}$ & Statistics \\
\hline \multirow{4}{*}{$\begin{array}{l}\text { Waste } \\
\text { disposal } \\
\text { behaviors }\end{array}$} & Low & 20 & 3.20 & 1.14 & \multirow{4}{*}{$\begin{array}{l}\text { Equal variances } \\
\mathrm{F}=0.82\end{array}$} & 22 & 3.00 & 1.02 & \multirow{4}{*}{$\begin{array}{l}\text { Equal variances } \\
\mathrm{F}=9.09 * * *\end{array}$} \\
\hline & Moderate & 89 & 3.36 & .94 & & 91 & 3.15 & .90 & \\
\hline & Very high & 42 & 3.42 & .97 & & 24 & 3.73 & .94 & \\
\hline & Total & 193 & 3.40 & .94 & & 193 & 3.40 & .94 & \\
\hline \multirow{3}{*}{$\begin{array}{l}\text { Green } \\
\text { purchasing } \\
\text { behaviors }\end{array}$} & High & 42 & 3.57 & .66 & \multirow{3}{*}{$\begin{array}{l}\text { Unequal } \\
\text { variances } \\
\mathrm{F}=1.95\end{array}$} & 56 & 3.60 & .81 & \multirow{3}{*}{$\begin{array}{l}\text { Equal variances } \\
\mathrm{F}=6.73 * * *\end{array}$} \\
\hline & Very high & 42 & 3.60 & .97 & & 24 & 3.94 & .71 & \\
\hline & Total & 193 & 3.42 & .83 & & 193 & 3.42 & .83 & \\
\hline \multirow{3}{*}{$\begin{array}{l}\text { Reuse and } \\
\text { recycle } \\
\text { behaviors }\end{array}$} & Low & 20 & 3.98 & .87 & \multirow{3}{*}{$\begin{array}{l}\text { Equal variances } \\
\mathrm{F}=1.87\end{array}$} & 22 & 3.93 & .89 & \multirow{3}{*}{$\begin{array}{l}\text { Equal variances } \\
\mathrm{F}=4.29^{* * *}\end{array}$} \\
\hline & Moderate & 89 & 3.92 & .88 & & 91 & 3.85 & .85 & \\
\hline & High & 42 & 4.13 & .77 & & 56 & 4.33 & .77 & \\
\hline \multirow{3}{*}{$\begin{array}{l}\text { Waste } \\
\text { avoidance } \\
\text { behaviors }\end{array}$} & High & 42 & 3.22 & .80 & \multirow{3}{*}{$\begin{array}{l}\text { Equal variances } \\
\mathrm{F}=0.78\end{array}$} & 55 & 3.53 & .72 & \multirow{3}{*}{$\begin{array}{l}\text { Equal variances } \\
\mathrm{F}=3.32 * *\end{array}$} \\
\hline & Very high & 41 & 3.44 & .94 & & 24 & 3.49 & .91 & \\
\hline & Total & 192 & 3.31 & .80 & & 192 & 3.31 & .80 & \\
\hline
\end{tabular}

Since the tests of homogeneity of variances showed equal variances across groups (sig $>0.05$ ) in all types of SWMBs (see Table 4), the results of the ANOVA analyses could be used for the effect of perceived severity on SWMBs. According to these results, there was a significant effect of perceived severity on the levels of engagement in waste disposal behaviors $(F(2,190)=2.80, p=0.063)$ and reuse and recycle behaviors $(\mathrm{F}(2,190)=6.34, \mathrm{p}=0.002)$. Post hoc comparisons using the LSD test 
indicated that the mean score of the level of engagement in waste disposal behaviors for moderate perceived severity was significantly lower than the high perceived severity. In addition, the mean score of the level of engagement in reuse and recycle behaviors for moderate perceived severity was significantly lower than very high perceived severity, whereas, there was not a significant difference between moderate and high perceived severity. Considering the effect of perceived vulnerability on SWMBs, the tests of homogeneity of variances showed equal variances across groups (sig $>0.05)$ in all types of SWMBs, except waste disposal behaviors. Therefore, the results of the Welch's t-test were used instead of the regular ANOVA test; these results revealed no significant effect of perceived vulnerability on waste disposal behaviors. The results of the ANOVA tests revealed the significant effect of perceived vulnerability on the levels of engagement in reuse and recycle behaviors ( $\mathrm{F}(3$, $189)=3.45, \mathrm{p}=0.018)$ and waste avoidance behaviors $(\mathrm{F}(3,188)=2.95, \mathrm{p}=0.034)$. Post hoc comparisons using the LSD test indicated that the mean score of the level of engagement in reuse and recycle behaviors for low perceived vulnerability was significantly lower than high and very high perceived vulnerability, whereas, the mean score for the moderate perceived vulnerability was significantly lower than that of the very high perceived vulnerability. For the avoidance behaviors, post hoc comparisons indicate that the mean score for the low perceived vulnerability was significantly lower than the moderate, high, and very high perceived vulnerability, whereas, other comparisons did not show a significant difference.

Table 4. Differences in means of SWMB engagement scores given by respondents who exhibited different levels of estimated threat.

\begin{tabular}{|c|c|c|c|c|c|c|c|c|c|}
\hline \multirow{2}{*}{ SWMB } & \multirow{2}{*}{ Threat appraisal } & \multicolumn{4}{|c|}{ Severity } & \multicolumn{4}{|c|}{ Vulnerability } \\
\hline & & $\mathrm{N}$ & Mean & SD & Statistics & $\mathrm{N}$ & Mean & SD & Statistics \\
\hline \multirow{5}{*}{$\begin{array}{l}\text { Waste } \\
\text { disposal } \\
\text { behaviors }\end{array}$} & Low & & & & \multirow{5}{*}{$\begin{array}{l}\text { Equal variances } \\
\mathrm{F}=2.80^{*}\end{array}$} & 17 & 2.91 & 1.28 & \multirow{5}{*}{$\begin{array}{l}\text { Unequal variances } \\
\mathrm{F}=1.88\end{array}$} \\
\hline & Moderate & 24 & 3.04 & .87 & & 55 & 3.29 & 0.67 & \\
\hline & High & 74 & 3.55 & .81 & & 78 & 3.53 & 0.97 & \\
\hline & Very high & 95 & 3.37 & 1.04 & & 43 & 3.50 & 0.99 & \\
\hline & Total & 193 & 3.40 & .94 & & 193 & 3.40 & 0.94 & \\
\hline \multirow{5}{*}{$\begin{array}{l}\text { Green } \\
\text { purchasing } \\
\text { behaviors }\end{array}$} & Low & & & & \multirow{5}{*}{$\begin{array}{l}\text { Equal variances } \\
\mathrm{F}=0.39\end{array}$} & 17 & 3.12 & 0.78 & \multirow{5}{*}{$\begin{array}{l}\text { Equal variances } \\
\mathrm{F}=2.04\end{array}$} \\
\hline & Moderate & 24 & 3.33 & .82 & & 55 & 3.35 & 0.72 & \\
\hline & High & 74 & 3.39 & .81 & & 78 & 3.42 & 0.84 & \\
\hline & Very high & 95 & 3.47 & .86 & & 43 & 3.65 & 0.93 & \\
\hline & Total & 193 & 3.42 & .83 & & 193 & 3.42 & 0.83 & \\
\hline \multirow{5}{*}{$\begin{array}{l}\text { Reuse and } \\
\text { recycle } \\
\text { behaviors }\end{array}$} & Low & & & & \multirow{5}{*}{$\begin{array}{l}\text { Equal variances } \\
\mathrm{F}=6.34^{* * *}\end{array}$} & 17 & 3.59 & 0.91 & \multirow{5}{*}{$\begin{array}{l}\text { Equal variances } \\
\mathrm{F}=3.45^{* *}\end{array}$} \\
\hline & Moderate & 24 & 3.60 & .87 & & 55 & 3.94 & 0.88 & \\
\hline & High & 74 & 3.95 & .83 & & 78 & 4.08 & 0.85 & \\
\hline & Very high & 95 & 4.24 & .83 & & 43 & 4.31 & 0.77 & \\
\hline & Total & 193 & 4.05 & .86 & & 193 & 4.05 & 0.86 & \\
\hline \multirow{5}{*}{$\begin{array}{l}\text { Waste } \\
\text { avoidance } \\
\text { behaviors }\end{array}$} & Low & & & & \multirow{5}{*}{$\begin{array}{l}\text { Equal variances } \\
\mathrm{F}=0.44\end{array}$} & 17 & 2.86 & 0.83 & \multirow{5}{*}{$\begin{array}{l}\text { Equal variances } \\
\mathrm{F}=2.95^{* *}\end{array}$} \\
\hline & Moderate & 24 & 3.17 & .77 & & 55 & 3.39 & 0.70 & \\
\hline & High & 73 & 3.32 & .72 & & 77 & 3.25 & 0.83 & \\
\hline & Very high & 95 & 3.34 & .87 & & 43 & 3.50 & 0.82 & \\
\hline & Total & 192 & 3.31 & .80 & & 192 & 3.31 & 0.80 & \\
\hline
\end{tabular}

Notes: $\mathrm{N}=193 ;{ }^{*} \mathrm{p}<0.1, * * \mathrm{p}<0.05, * * * \mathrm{p}<0.01$.

\section{Discussions and Implications for the Development of Communication Campaigns}

This study considered that behavioral change is important to the reduction of waste management problems in cities. Protection motivation theory was employed to investigate whether threat appraisal and copping appraisal would effect SWMBs. According to the results of the one-way ANOVA analyses, respondents' perceived response efficacy did not influence all types of SWMBs. On the contrary, perceived self-efficacy had a significant effect on all types of SWMBs. This implies that people will decide to perform SWMBs if they think that it is possible to perform them. This finding is in the line with the investigation result conducted by Tabernero and Hernandez [29] which found that self-efficacy was highly influenced people's self-reported recycle behaviors. Self-efficacy was also found as a significant predictor of pro-environmental behaviors in many studies which applied the theory of planned behaviors (TPB) [30, 31]. Regarding the influence of threat appraisal on SWMBs, the result showed that not all types of SWMBS were influenced by perceived severity and vulnerability. It is noteworthy that green purchasing behaviors were not 
significantly affected by either perceived severity or vulnerability. However, individual decisions to practice green purchasing might be dependent on other factors such as environmental attitudes, knowledge, and income level. This is because green purchasing practices sometimes cause additional expenditures and rely more on an individual's general environmental awareness than the intention to protect themselves from environmental threats caused by waste disposal. Reuse and recycle behaviors were affected by both the respondents' perceived severity and vulnerability. This finding is related to the results from other previous studies that also found the relationship between individual perceived environmental risks and pro-environmental behavior such as electric vehicle adoption [25-27]. For this study, it could be explained that reuse and recycle behaviors are simple well-known measures that could be practiced in general. Some types of behaviors such as double-sided printing and using single-sided paper for writing notes could also provide some economic benefits. When people feel that they are facing risks, they might first decide to perform the behavior that can be carried out simply and has no cost. People might feel that the severity of adverse consequences and their vulnerability would be minimized in practicing reuse and recycle behaviors. As found in the study of Homburg and Stolberg [28], the combination of perceived risks and self-efficacy could motivate people to engage in pro-environmental behaviors. The results of the statistical analyses also revealed the significant effect of perceived vulnerability on waste avoidance behaviors. Since waste avoidance is also a simple and no cost waste management behavior, the reason for explaining this effect is similar to reuse and recycle behaviors. In addition to being influenced by self-efficacy, waste disposal behaviors were affected by perceived severity. This is noteworthy because the nature of waste disposal behaviors potentially reduces environmental problems caused by ineffective waste disposal. Overall, it could be suggested that the protection motivation theory is well suited to the investigation of some types of SWMBs, particularly low-cost and simple waste management behaviors.

Additionally, based on the findings of this study, communication campaigns for enhancing waste management behaviors could be suggested. Apparently, communicating information that could enhance people' perceived self-efficacy might positively influence people's engagement in all types of SWMBs. Those information might be, for instance, how to do waste separation or how to make use of solid waste. Communication of information relevant to severity of adverse consequences caused by environmental contamination that is generated from waste disposals also potentially enhance the motivation to engage in reuse and recycle behaviors and waste disposal behaviors, since the findings revealed that people's perceived severity significantly effected those two types of SWMBs. This study also found that the difference in level of perceived vulnerability also significantly caused the different level of engagement in reuse and recycle behaviors and waste avoidance behaviors. Therefore, communicating information relevant to an individual's perceived vulnerability to environmental contamination, such as types of health impairment caused by polluted air or water, might be able to enhance those two types of SWMBs as well. In conclusion, it could be stated that encouraging people to engage in each types of SWMBS requires different communication strategies.

\section{Conclusions}

This study applied the protection motivation theory (PMT) to investigate citizens' engagement in sustainable waste management behaviors (SWMBs). Based on PMT, four factors, including perceived severity of catastrophic consequences of environmental pollutants caused by waste disposal processes, perceived probability of receiving impacts, perceived response efficacy, and self-efficacy, were investigated regarding their effect on citizens' engagement in SWMBs-including waste avoidance, green purchasing behaviors, reuse and recycle, and waste disposal behaviors. The one-way analyses of variances (ANOVA) were performed, and the results revealed that perceived response efficacy did not influence all types of SWMBs. In contrast, perceived self-efficacy had a significant effect on all types of SWMBs. Perceived severity had a significant influence on waste disposal behaviors and reuse and recycle behaviors; whereas, perceived probability of receiving impacts or vulnerability had a significant effect on reuse and recycle behaviors and waste avoidance 
behaviors. Based on the findings, this study suggested that PMT can be used to investigate some types of SWMBs and to promote the citizens' practices of SWMBs, and that different communication campaigns should be developed based on citizens' threat appraisal and coping appraisal.

Acknowledgments: This study was funded by School of Liberal Arts, King Mongkut's University of Technology Thonburi, Thungkru, Bangkok City, Thailand. The authors would like to acknowledge all participants who completed questionnaire sheets.

Conflicts of Interest: The author declares no conflict of interest.

\section{References}

1. Department of Public Cleansing. 2000. Waste Minimization Project in Bangkok City, Department of Public Cleansing, Bangkok Metropolitan Administration. [available only in Thai]

2. Department of Public Cleansing. 2005. Solid Waste and Night soil Management in Bangkok, Department of Public Cleansing, Bangkok Metropolitan Administration.

3. US-EPA. 2013. Non-hazardous solid waste management hierarchy, Retrieved from http://www.epa.gov/solidwaste/nonhaz/municipal/hierarchy.htm (Retrieved 20 March 2016).

4. Papargyropoulou, E., Lozano, R., Steinberger, J.K., Wright, N., Ujang, Z.B. 2014. The food waste hierarchy as a framework for the management of food surplus and food waste, Journal of Cleaner Production, 76, 106-115.

5. Permana, A.S., Towolioe, S., Aziz, N.A, Ho, C.S. 2015. Sustainable solid waste management practices and perceived cleanliness in a low income city, Habitat International, 49, 197-205.

6. Knauf, M. 2015. Waste hierarchy revisited - an evaluation of waste wood recycling in the context of EU energy policy and the European market, Forest Policy and Economics, 54, 58-60.

7. UC Davis. 2008. The 4 R's of waste reduction. Retrieved from http://sustainability.ucdavis.edu/topics/waste_reduction/index.html

8. First Nations of Quebec and Labrador Sustainable Development Institute. 2008. Reduce, Reuse, Recycle and Recover Waste: A 4R's guide for the First Nations communities of Quebec and Labrador. Retrieved from www.iddpnql.ca/an/documents/4rsguide.pdf

9. ECOTEC Research and Consulting Ltd. 2000. Beyond the bin: The economics of waste management options. Retrieved from www.foe.co.uk/resource/reports/economics waste options.pdf

10. European Parliament and European Council. 2008. Directive 2008/98/EC on waste (Waste Framework Directive). Retrieved December 12, 2014, from ec.europa.eu/environment/waste/framework/

11. Ajzen, I. 1991. The theory of planned behavior. Organizational Behaviors and Decision Processes, 50, 179-211.

12. Rogers, R.W., 1975. A Protection Motivation Theory of fear appeals and attitude change. Journal of Psychology, 91, 93-114.

13. Rogers, R.W., 1983. Cognitive and physiological processes in fear appeals and attitude change: a revised theory of protection motivation. In: Cacioppo, B.L., Petty, R.E. (Eds.), Social Psychophysiology: A Sourcebook. Guilford Press, London.

14. Prentice-Dunn, S., Rogers, R.W., 1986. Protection motivation theory and preventive health: beyond the health belief model. Health Educ. Res. 1, 153-161.

15. El-Fadelf, M., Findikakis, A.N., \& Leckie, J.O. 1997. Environmental Impacts of Solid Waste Landfilling. Journal of Environmental Management, 50(1), 1-25. 
16. Wu, Y., Stanton, B. F., Li, X., Galbraith, J., Cole, M. 2005. Protection motivation theory and adolescent drug trafficking: Relationship between health motivation and longitudinal risk involvement, Journal of Pediatric Psychology, 30 (2), 127-137.

17. Kelly, M.P., Barker, M. 2016. Why is changing health-related behavior so difficult? Public Health, 136, 109-116.

18. Grothmann, T., Patt, A., 2005. Adaptive capacity and human cognition: the process of individual adaptation to climate change. Global Environmental Change, 15 (3), 199-213.

19. Martin, I., Bender, H., Raish, C., 2007. What motivates individuals to protect themselves from risks: the case of Wildland fires. Risk Analysis, 27 (4), 887-900.

20. Bubeck, P., Botzen, W.J.W., Aerts, J.C.J.H., 2012. A review of risk perceptions and other factors that influence flood mitigation behavior. Risk Analysis, 32 (9), 1481-1495.

21. Warriner, G. K., McDougall, G. H., Claxton, J. D. 1984. Any data or none at all? Living with inaccuracies in self-reports of residential energy consumption. Environmental and Behavior, 16, 503-526.

22. Fujii, E.T., Hennesy, M., Mak, J. 1985. An evaluation of the validity and reliability of survey response data on household electricity conservation. Environmental Reviews, 9, 93-104.

23. Boer, H., Seydel, E. 1996. Protection motivation theory, in Connor M, Norman P (eds.): Predicting Health Behavior: Research and Practice with Social Cognition Models. Buckingham, PA, Open University Press, pp. 95-120.

24. Stern, P.C., 2000. Towards a coherent theory of environmentally significant behavior. Journal of Social Issues. 56, 407-424.

25. Kahn, M.E., 2007. Do greens drive Hummers or hybrids? Environmental ideology as a determinant of consumer choice. Journal of Environmental Economics and Management. 54, 129-145.

26. Ozaki, R., Sevastyanova, K., 2011. Going hybrid: an analysis of consumer purchase motivations. Energy Policy. 39, 2217-2227.

27. Bockarjova, M., Steg, L., 2014. Can Protection Motivation Theory predict pro-environmental behavior? Explaining the adoption of electric vehicles in the Netherlands. Global Environmental Change. 28, 276-288.

28. Homburg, A., Stolberg, A., 2006. Explaining pro-environmental behavior with a cognitive theory of stress. Journal of Environmental Psychology. 26, 1-14.

29. Tabernero, C., Hernandez, B., 2010. Self-Efficacy and intrinsic motivation guiding environmental behavior. Environment and Behavior. 43(5), 658-675.

30. Ajzen, I., Fishbein, M. 2004. Attitudes and the attitude-behavior relation: reasoned and automatic processes. John Wiley.

31. Fernandez-Manzanal, R., Serra, L.M., Morales, M.J., Carrasquer, J., Rodriguez-Barreiro, L.M., Del Valle, J., Murillo, M.B. 2015. Environmental behaviors in initial professional development and their relationship with university education. Journal of Cleaner Production. 108, 830-840.

(C) 2016 by the author; licensee Preprints, Basel, Switzerland. This article is an open access article distributed under the terms and conditions of the Creative Commons by Attribution (CC-BY) license (http://creativecommons.org/licenses/by/4.0/). 